\title{
Anthropological and Forensic Aspects of Odontological Variation in Two Contemporary Australian Populations
}

\author{
Alison S. ChIU AND Denise Donlon \\ Shellshear Museum, Department of Anatomy and Histology, University of Sydney, New South Wales, 2006, Australia
}

\begin{abstract}
The utilization of odontometric variation as a discriminator between modern human groups continues to decline, despite its value in both anthropological and forensic contexts. Traditional odontometric methods, coupled with advanced statistical methods, are applied to illustrate the continuing usefulness of these techniques. The ability to discriminate between the major population groups (Caucasoid and Mongoloid) in the Sydney region of Australia, based on dental dimensions, is extremely valuable in the forensic identification of individuals. Furthermore, metric variation in the dentition of these contemporary populations is poorly understood in this region of the world. The utility of variation in tooth dimensions in discriminating between these two groups is explored. Dental stone casts of the permanent maxillary and mandibular dentition of 198 individuals were made, and mesiodistal and buccolingual crown dimensions were recorded for each tooth. Both univariate and multivariate analyses were used to investigate differences in linear and areal dimensions, as well as the predictive value of these measures in a forensic context, using discriminant function analysis (DFA). DFA produced separation of Caucasoids and Mongoloids with a success rate of 93.9\% on the basis of these measurements. Separation of the groups was most apparent in the mesiodistal and buccolingual dimensions of the maxillary first premolar $\left(\mathrm{P}^{1)}\right.$, the mesiodistal diameter of the maxillary second premolar $\left(\mathrm{P}^{2}\right)$, and the mesiodistal dimension of the mandibular first premolar $\left(\mathrm{P}_{1}\right)^{1}$. The results from this study further highlight the usefulness of dental metrics in forensic applications and contribute to our knowledge of the variation of these features in contemporary human populations. ${ }^{2}$
\end{abstract}

\section{INTRODUCTION}

The variation in the size and shape of the human adult dentition has been used widely to discriminate groups on the basis of racial identity, or population affinity. The durability of the human skeleton, especially the teeth, provides a basis for determination of population affinity from human remains, for example, in the forensic and/or archaeological setting. Further, teeth being the only hard tissues directly observable in the living human, permit noninvasive techniques (e.g., dental casts) to study contemporary populations. Here we utilize dental casts to study two of the major contemporary populations residing in Sydney, Australia. These population groups are Caucasoid and Mongoloid, defined broadly for the exploratory purposes of assessing the feasibility of discriminating between these two groups.

Tooth length and width have become the most extensively documented anthropometric features, utilized for such purposes as estimating biological distance between human populations, and evolutionary considerations (Kieser, 1990). In the mid twentieth century odontometric studies attempted to approximate tooth shape, through indices, such as the crown index (bl/md x 100) and crown module ((bl+md)/2) (e.g., Moorrees, 1957; Rosenzweig, 1970).

The traditional approach to odontometrical studies has been criticized by some investigators for being too simplistic (Lavelle, 1984), too limited (Goose, 1963), overemphasized (Corruccini, 1977b, 1978), underutilizing the available information (Wood and Abbott, 1983), and lacking biological meaning (Corruccini, 1977a). Many of the same concerns have not been expressed for the use of crown areas: a product of mesiodistal and buccolingual dimensions ( $\mathrm{md} \mathrm{x} \mathrm{bl}$ ). In overcoming the problems with 
conventional odontometrics, the description of definable tooth crown landmarks on the occlusal surface (Biggerstaff, 1969a), combined with a reliable and accurate method to record them (Biggerstaff, 1969b), led to detailed measurements of the tooth crown. Applications of this methodology have focused on separating groups comprised of various population affinities (Lavelle, 1978, 1984), as well as taxa (Corruccini, 1977b, 1978; Wood and Abbott, 1983). The main drawback to these techniques is the reliance on unworn teeth for data collection, a difficulty when dealing with archaeological collections. Dental work is also likely to obscure landmarks, causing difficulties in studying contemporary populations. Many studies also rely on a single tooth, examining within-tooth variation only.

Here, we use mesiodistal and buccolingual diameters of all maxillary and mandibular teeth in the dental arcades (excluding M3) as the basis for assessing the feasibility of separating Caucasoids and Mongoloids. Further, summed mesiodistal diameters ( $\left.\sum \mathrm{md}\right)$, summed buccolingual diameters $\left(\sum \mathrm{bl}\right)$, and crown areas (md $\mathrm{x} \mathrm{bl)}$ are computed for the anterior and posterior (postcanine) teeth and compared in Caucasoids and Mongoloids. Mizoguchi (1981) and Kieser and Groeneveld (1987) have suggested that these two tooth groups represent functional units that characterize the dental arch. The anterior tooth group is further divided into incisors and canine, since the idea of independent control mechanisms of these regions has not been eliminated and is presently unclear.

For all the objections to traditional odontometrical methods, major problems have existed at the level of analysis. Most studies which compare the dental metric variation of two or more groups have focused almost exclusively on individual teeth as units of study, restricting the analysis to tooth-by-tooth inspection (Harris and Rathbun, 1991). With modern computers the realm of multivariate statistics has been available for several decades. Through the use of both univariate and multivariate techniques, populations can be defined on the basis of tooth size alone (Mayhall, 1992). The use of both methods is, in fact, advocated (Potter, 1972). We support this approach by employing the Student's t-test, canonical variate analysis (CVA), and discriminant function analysis (DFA).

A strong genetic component of crown size has long been recognized, with the majority of data suggesting the involvement of multifactorial genetic factors in controlling odontometric traits (Sofaer, 1970). However, an unquestionable environmental component exists in the determination of tooth size. The exact proportions of the genetic and environmental components in odontometric variability remain controversial (Goose, 1967). A value of $64 \%$ of the total variability has been assigned directly to genetic factors (Townsend and Brown, 1978), emphasizing the importance of previously overlooked nongenetic influences in the determination of tooth size. This finding may have important considerations for the use of tooth crown dimensions in the forensic setting. We have restricted our investigation to population groups located in a limited geographical region.

Contemporary populations considered presently have been extensively studied with respect to non-metric dental traits. Highly successful separation of Caucasoids and Mongoloids has been achieved due to the recognition of high incidences of shovel-shaped incisors in Mongoloid populations and the cusp form of Carabelli's trait in Caucasoid populations (Hrdlička, 1920; Dahlberg, 1951; Carbonell, 1963; Hanihara, 1968). However, for several reasons the use of these traits may be limited. Non-metric traits may vary along a gradient within the dentition in accordance with Butler's field theory (Butler, 1939; Dahlberg, 1945), where expression is the most intense on the most mesial tooth of each class.

Shovel-shaped incisors are confined to the anterior teeth, which, being single-rooted, (Krogman and Isscan, 1986) are frequently lost postmortem, a consideration in the forensic setting where maxillary central incisors are missing. Shovel-shaped incisors clearly discriminate major regional groups, although other nonmetric crown traits associated with the "Mongoloid dental complex" (e.g., protostylid, sixth cusp) (Hanihara, 1967) do not distinguish as clearly between populations as do shovel-shaped incisors. Variations in frequencies exist within all populations. In Mongoloids, as is illustrated by the proposed subdivision into Sinodonty and Sundadonty, the former generally exhibit intensified traits (Turner, 1985, 1989, 1990a,b). 
Observations of dental non-metric traits can be subjective. Only within the past fifty years have threedimensional graded standards for scoring procedures been devised (Dahlberg, 1956; Hanihara, 1961; Turner et al., 1991). Also, particular problems have been reported with scoring procedures of Carabelli's trait (Kieser and van der Merwe, 1984).

The objectivity and reliability of odontometric studies (Moorrees, 1957) has led us to investigate the differences that exist in tooth crown dimensions and to quantify the degree of separation achievable in Caucasoid and Mongoloid groups residing in the Sydney area.

The investigation of sexual dimorphism follows in a later study and will assess the feasibility of separation of the sexes, as well as the nature of sexual differences, within both Caucasoids and Mongoloids. Possibly, sex differences are unique to a given population group (Hanihara, 1978; O'Higgins et al., 1990). Therefore, population affinity variation and sex variation require independent consideration. Consequently, we caution that when the data allow independent classification by sex, indeed as in the case of Mongoloids and Caucasoids, sex within each population affinity is best described by a unique discriminant function. Determination of the population affinity first and then the sex of unprovenanced remains by the function appropriate to sex within that population affinity is the wisest.

\section{MATERIALS AND METHODS}

A sample of 198 dental stone casts (from alginate impressions) of contemporary Caucasoid (44 male, 57 female; total 101) and Mongoloid (53 male, 44 female; total 97) subjects were prepared from volunteer subjects living in the Sydney region. The majority of participants were recruited through the student body of the Faculty of Dentistry, University of Sydney, Australia. Age of individuals ranged from young adult to middle age adult (18-50), thereby more likely to display the full permanent dentition than younger or older persons.

Population affinity of individuals comprising the sample, as well as biological parents, was assessed through the use of questionnaires. Both parents had to originate from the target sample in order to be included in the study. Most of the Mongoloid sample originated from South-East China, Vietnam, and Hong Kong. Most of the Caucasoid sample originated from Northern Europe. Independent visual estimation of Caucasoid or Mongoloid derivation confirmed the information obtained from questionnaires. The purpose of this was to informally assess the forensic utility of population affinity, since the identification of an individual as a member of a particular population group in life is commonly reflected by physical appearance.

No attempt was made to assess specific prenatal environmental influences which may affect tooth size. Also, no obvious reason was found for excluding from the sample those individuals who have undergone orthodontic treatment, since the final shape and size of the tooth crown is determined well before its eruption into the mouth (Kieser, 1990) and, therefore, unaffected. However, recently we learned that upon removal of orthodontic prostheses, the tooth surface may be stripped very slightly, having the potential to slightly decrease the buccolingual dimension of the tooth crown (personal communication, Dr. Robert B.J. Dorion, Forensic Odontologist, Laboratory of Forensic Medicine, Montreal, Quebec). Presumably, this effect is of such small magnitude it does not significantly influence the results, and will be random in affecting either population group.

Mesiodistal and buccolingual linear measurements of the tooth crown were made using dial calipers with specially machined tips, which allowed insertion between the teeth. Measurements were recorded to the nearest $0.05 \mathrm{~mm}$. All permanent teeth in maxillary and mandibular dental arches, except the third molars, were included. All measurements were taken by the primary author and are defined as follows: Mesiodistal diameter (md) "...the greatest distance between the approximate surfaces of the crown with a sliding caliper held parallel to the occlusal-surface of the crown. Where a tooth was rotated or malposed in relation to the dental arch, the measurement was taken between the points on the approximate surfaces of the crown where the worker judged that contact with neighboring teeth 'normally' should have occurred" (Barrett et al., 1963). 
This method of measurement was chosen for its congruence with methods used by forensic workers in the Sydney region (personal communication, Associate Professor Christopher J. Griffiths, Director of Diagnostic Dentistry, Dental Clinical School, Westmead Hospital and Chief Forensic Odontologist, NSW Institute of Forensic Medicine, Sydney, Australia).

Buccolingual diameter $(\mathrm{bl})$ "...the greatest distance between the labial or buccal surface and the lingual surface of the tooth crown ... was measured ... with a sliding caliper held at right angles to the mesiodistal crown diameter of the tooth" (Barrett et al., 1964).

The variation in tooth size is of small dimensions, emphasizing the importance of reducing possible sources of error. Systematic errors, arising from limitations in the instruments and the materials, were minimized. Limiting possible inaccuracies through operational procedure included adherence to the prescribed mixing time of alginate (Algident, Australia), compliance with correct tray filling techniques, and pouring of casts with dental stone (Boral Investo, Australia) as soon as possible after removal of the impression from the mouth. However, a slight linear distortion, regardless of the technique or material used, is reported (Lysell and Myrberg, 1982). The use of stone casts fabricated from alginate impressions as a representation of actual tooth size is widely used and preferred to taking direct measurements from the mouth (Hunter and Priest, 1960). Modified calipers (Mitutoyo, Japan), as described above, were used. The following criteria were also established. Teeth were rejected on the basis of carious lesions or restorations, which affected the mesiodistal or buccolingual diameters of the crown, including deposits such as plaque or calculus reproduced on the cast. Malformed or incompletely/partially erupted teeth were excluded from measurement, as well as those teeth rendered immeasurable due to faulty casts or impression flaws.

Apparent loss of tooth substance due to occlusal attrition or those teeth in which interproximal attrition had markedly reduced the crown diameter were also not measured. Differences in the extent to which worn teeth are included in statistical work occur (Brothwell, 1967). Slight differences in measuring technique amongst observers (Utermohle et al., 1983), as well as the value for a given measurement from the same observer, are likely to occur. These experimental errors were minimized by assessing the precision and accuracy of repeat measurements intra-observer and inter-observer, via the double determination of Dahlberg (also known as the method error statistic) (Dahlberg, 1940).

\section{Statistical Manipulations}

Differences between groups are initially assessed through the Student's $t$-test to provide some indication of the significance of differences between the means of Caucasoids and those of Mongoloids on each tooth dimension. In assessing the achievable degree of group separation, canonical variates analysis (CVA) determines the linear combinations of variables that maximizes group differences, relative to variation within groups. Variables that contribute most to the discriminatory power of the derived functions are identified though their correlations with the discriminant function. Loadings greater than \pm 0.30 are interpreted as part of the variate (Tabachnick and Fidell, 1996).

The success of the linear combination of variables in separating Caucasoids and Mongoloids from each other based on tooth crown dimensions is evaluated by discriminant function analysis (DFA), by assigning cases to groups, and constructing a confusion matrix, a breakdown of classified and misclassified cases. Direct DFA is used, entering all variables at the one step. Tolerance levels are set routinely to protect against the statistical instability caused by multicollinearity and singularity, an important consideration with the reported strong positive collinearity between tooth crown variables (Moorrees and Reed, 1964). Although CVA precedes the DFA, for ease of interpretation of results, the multivariate techniques utilized here will be discussed in combination. SPSS (release 6.1 for the Macintosh) is used for all statistical manipulations described hitherto, except the randomization procedure (vide infra).

The statistical significance of the classification success rates is examined using a randomization method from The MV-NUTSHELL Brochure (Wright, 1994), insuring that the results of the multivariate analyses 
do not occur by chance alone (Manly, 1991). The method of randomization utilized in the present study is one that makes no assumptions about the distributions of the variables in the populations from which the samples are drawn (personal communication, Richard VS. Wright, Emeritus Professor of Anthropology, University of Sydney, Australia). The mean scores for each category (e.g., Caucasoid, Mongoloid), and the difference between the means is found. Each individual in the original data set is randomly assigned to one of the two groups. The difference between the two means based on this randomized allocation into population group is then determined. This is repeated 99 times, and the categories are randomized across the sample in each analysis. The test therefore involves comparing the observed difference between the groups with the distribution of differences found with random allocation (Manly, 1991). With the randomization procedure, computation of confidence limits for the success rates achieved from randomizing the data is possible. At the $99 \%$ confidence limit, the probability of another success rate derived from the randomized within the limits is $99 \%$. If the actual success rate falls outside the confidence limits established for the randomized data, it is considered significant $(\mathrm{p}<0.01)$. That is, the differences in tooth size between groups have not occurred by chance alone.

In addition to utilizing mesiodistal and buccolingual crown diameters to explore variation between Caucasoids and Mongoloids, summed mesiodistal crown diameters, summed buccolingual crown diameters, and crown areas of incisors, canine, and postcanine teeth are compared between groups. To compare the degree of differences, the total difference is divided by the number in a tooth group (i.e., two in the incisor region, one for the canine, and four in the postcanine region). This effectively gives the average difference between groups per tooth and counterbalances the additive effects of tooth groups with a greater number of objects than other tooth groups.

\section{RESULTS}

The intra-observer measurement errors, as indicated by the Dahlberg statistic (Dahlberg, 1940), range from $0.03 \mathrm{~mm}$ to $0.07 \mathrm{~mm}$. Inter-observer errors range from 0.10 to $0.18 \mathrm{~mm}$. As expected, inter-observer errors are greater in magnitude than intra-observer errors. However, they remain comparable with the double determination results of other investigators (e.g., Townsend, 1976), are very small in magnitude, and are unlikely to effect subsequent analyses. Only two cases in which a tooth dimension was not selected for measurement by the primary author and measured by a second observer occurred, indicating a more conservative approach to selection criteria by the investigator engaged in data collection than the secondary observer.

Detailed preliminary analyses of each variable were performed to investigate the accuracy of the data files, the distributions of observed values, inter-trait correlations, and the presence of outliers or extreme values. While perfect distributions are probably unobtainable, few problems were noted. The results are not discussed here. Suffice to say that the central limit theorem reassures us that with large sample sizes, sampling distributions of means are normally distributed regardless of the distributions of variables.

Asymmetry was assessed prior to analyses with paired Student's $t$-tests $(\mathrm{p}<0.05)$. The Caucasoid pooled sex group has nine significantly asymmetric variables: $\mathrm{I}^{1}$ and $\mathrm{I}_{1}(\mathrm{bl}), \mathrm{I}^{2}(\mathrm{md}), \mathrm{UC}(\mathrm{bl}), \mathrm{P}^{2}(\mathrm{md}), \mathrm{M}_{1}$ (md and bl), $\mathrm{M}^{2}$ (bl), and $\mathrm{M}_{2}(\mathrm{bl})$. More variables are significantly asymmetric in the buccolingual dimension than in the mesiodistal dimension. The Mongoloid sample is significantly asymmetric in $\mathrm{I}^{2}(\mathrm{md}), \mathrm{UC}(\mathrm{md})$, and $\mathrm{M}_{1}$ and $\mathrm{M}_{2}$ (bl). At $\mathrm{p}=0.05$, the number of asymmetric measurements expected by chance alone is one to two for each sub-sample, or about four overall. Clearly, true asymmetry occurs across the dentition. However, in accordance with anthropological convention, the left side of the dentition was used for statistical analyses (Lavelle, 1970). Analyses were also conducted for right hand side measurements, although the results are not presented. They will be discussed, albeit briefly, with regards only to general differences between results arising from left and right hand side measurements.

Missing data appeared to be randomly distributed throughout Caucasoid and Mongoloid groups, and were substituted with the within-group means to maximize the potential of the data for the multivariate 
analyses. Since the missing data lacked a pattern, consideration of omitting one or a few variables or deleting individuals from the analyses was not feasible. Leaving the data blank would have resulted in about half of the dataset being lost in multivariate analysis, since it handles complete data only. In total, the variables consisted of 28 measurements for each individual and all the original 198 cases were included.

\section{Univariate Results}

Results of Student's $t$-tests are found in Table 1 . Caucasoid and Mongoloid tooth crown dimensions differ significantly $(p<0.05)$ on 18 of a total 28 variables. This includes all variables in the mesiodistal dimension except $I^{1}, M^{2}$, and $M_{2}$. Relatively fewer variables in the buccolingual dimension are significantly different between groups, those being $I^{2}, P^{1}, P^{2} I_{1}, P_{1}, M_{1}$, and $M_{2}$.

The direction of differences is such that tooth crown dimensions of Mongoloids exceed those of Caucasoids in almost every instance. Exceptions to this are the mesiodistal diameter $\mathrm{M}^{2}$ and buccolingual diameters of the mandibular anterior teeth, that is, $\mathrm{I}_{1}, \mathrm{I}_{2}$, and LC. Of these relatively larger Caucasoid measurements, only the formermost is significant.

Two variables $\left(\mathrm{P}^{2}(\mathrm{md}), \mathrm{M}^{1}(\mathrm{bl})\right.$ ) required the computation of $t$-tests using separate variances, since the assumption of homogeneity of variance (Levene's test) was violated. For both variables, this yielded very slight decreases in the $t$-values and standard errors of the difference, and small decreases in the degrees of freedom $(<10 \%)$, compared with calculations based on pooled variances. The significance values were unchanged.

\section{Multivariate Results}

Univariate analyses of equality of group means precedes the CVA and DFA. Since the missing data have been substituted with means, the groups become homogenized, thus potentially creating artificial separation of the groups. To assess this crudely, one-way analysis of variance (ANOVA) was performed on the two datasets that were utilized for univariate and multivariate analyses, in which the latter is modified by substitution of the missing values with within-group means. Although, no overall effect on whether or not variables show significant differences is seen, the effect of replacing missing values (in the 'new' dataset) has increased the $F$ values slightly, and subsequently each variable approaches $\mathrm{p}<0.01$ more closely, compared to the original dataset retaining missing values. The only

TABLE 1. Univariate differences (Student's t-test) of tooth crown diameters between Mongoloids and Caucasoids.

\begin{tabular}{|c|c|c|c|c|c|}
\hline Variable & df & $\begin{array}{l}\bar{x} \mathrm{M}- \\
\bar{x} \mathrm{C}^{\mathrm{l}}\end{array}$ & $\begin{array}{c}\text { SE of } \\
\text { difference }\end{array}$ & $\mathrm{t}$ & $\mathrm{p}(2 \text { tail })^{2}$ \\
\hline$I^{l} \quad(\mathrm{md})$ & 187.00 & 0.0718 & 0.082 & 0.87 & 0.384 \\
\hline $\mathrm{I}^{2} \quad(\mathrm{md})$ & 182.00 & 0.4855 & 0.089 & 5.47 & $0.000 * *$ \\
\hline $\mathrm{UC}(\mathrm{md})$ & 189.00 & 0.3513 & 0.066 & 5.30 & $0.000 * *$ \\
\hline $\mathrm{P}^{\prime} \quad(\mathrm{md})$ & 170.00 & 0.5641 & 0.071 & 7.97 & $0.000 * *$ \\
\hline $\mathrm{P}^{2} \quad(\mathrm{md})$ & 161.75 & 0.5359 & 0.067 & 8.02 & $0.000^{* *}$ \\
\hline $\mathrm{M}^{\mathrm{t}}$ (md) & 186.00 & 0.1762 & 0.082 & 2.14 & $0.034^{*}$ \\
\hline $\mathrm{M}^{2}(\mathrm{md})$ & 168.00 & -0.0276 & 0.090 & -0.31 & 0.760 \\
\hline $\mathrm{I}^{\prime} \quad$ (bl) & 178.00 & 0.0599 & 0.084 & 0.72 & 0.475 \\
\hline $\mathrm{I}^{2} \quad(\mathrm{bl})$ & 177.00 & 0.1969 & 0.091 & 2.17 & $0.031^{*}$ \\
\hline $\mathrm{UC}$ (bl) & 184.00 & 0.1168 & 0.095 & 1.22 & 0.223 \\
\hline $\mathrm{P}^{1} \quad$ (bl) & 170.00 & 0.5925 & 0.089 & 6.66 & $0.000 * *$ \\
\hline $\mathrm{P}^{2} \quad$ (bl) & 168.00 & 0.2229 & 0.093 & 2.41 & $0.017^{*}$ \\
\hline $\mathrm{M}^{1} \quad(\mathrm{bl})$ & 166.17 & 0.0022 & 0.083 & 0.03 & 0.979 \\
\hline $\mathrm{M}^{2} \quad(\mathrm{bl})$ & 171.00 & 0.0907 & 0.103 & 0.88 & 0.379 \\
\hline $\mathrm{I}_{1} \quad(\mathrm{md})$ & 185.00 & 0.2282 & 0.054 & 4.26 & $0.000 * *$ \\
\hline $\mathrm{I}_{2}(\mathrm{md})$ & 187.00 & 0.1712 & 0.058 & 2.95 & $0.004 * *$ \\
\hline LC (md) & 191.00 & 0.3030 & 0.062 & 4.88 & $0.000 * *$ \\
\hline$P_{1} \quad(m d)$ & 179.00 & 0.4201 & 0.062 & 6.75 & $0.000 * *$ \\
\hline$P_{2}(\mathrm{md})$ & 166.00 & 0.2598 & 0.066 & 3.94 & $0.000 * *$ \\
\hline $\mathrm{M}_{1}(\mathrm{md})$ & 176.00 & 0.3896 & 0.094 & 4.14 & $0.000 * *$ \\
\hline $\mathrm{M}_{2}(\mathrm{md})$ & 172.00 & 0.1098 & 0.095 & 1.15 & 0.251 \\
\hline$I_{1} \quad(b l)$ & 181.00 & -0.1882 & 0.068 & -2.75 & $0.007^{\star}$ \\
\hline $\mathrm{I}_{2} \quad(\mathrm{bl})$ & 180.00 & -0.0301 & 0.061 & -0.49 & 0.624 \\
\hline $\mathrm{LC}$ (bl) & 180.00 & -0.0269 & 0.083 & -0.32 & 0.747 \\
\hline P1 (bl) & 175.00 & 0.3896 & 0.075 & 5.18 & $0.000^{* *}$ \\
\hline $\mathrm{P}_{2} \quad(\mathrm{bl})$ & 166.00 & 0.0855 & 0.081 & 1.06 & 0.290 \\
\hline $\mathrm{M}_{1}(\mathrm{bl})$ & 175.00 & 0.2562 & 0.079 & 3.22 & $0.002^{* *}$ \\
\hline $\mathrm{M}_{2}$ (bl) & 177.00 & 0.1665 & 0.083 & 2.00 & $0.047 *$ \\
\hline
\end{tabular}

${ }^{\mathrm{i}} \mathrm{M}=$ Mongoloid, $\mathrm{C}=$ Caucasoid. $2^{*}(\mathrm{p}<0.05),{ }^{* *}(\mathrm{p}<0.01)$ 
exception to this is $\mathrm{I}_{2}(\mathrm{bl})$, where the converse trend was observed. Since substitution of missing values utilizing within-group means increases the likeness of each group and makes each group slightly more distinct from the other, the effect on $\mathrm{F}$ ratios is logical. The most marked example of the described effect is $\mathrm{P}_{2}(\mathrm{bl})$, where the initial computation yielded $\mathrm{F}=5.7856$, with $\mathrm{p}=0.0172$, clearly significant $(\mathrm{p}<0.05)$. The second computation, after missing values for this variable were replaced by within-group means, yielded $F=7.5904$ with $p=0.0064$, being highly significant $(p<0.01)$. Certainly, no $F$ value is altered from not significant to significant, or vice versa, as a result of replacing missing values.

Interdependencies between variables are examined through pooled within-group correlation matrices, derived from the averaged separate correlation matrices for each group. Few strong correlations exist, no doubt due to the inclusion of variables from only one side of the dental arch. The highest correlations $(>0.70)$ are found between equivalent measurements in the maxilla and mandible and in the same morphological class.

Differences between groups are generally small in proportion to the total variability for many of the variables. This is shown by Wilks lambda (Table 2). In descending order, the variables with the greatest differences in means across the two population groups (U statistic $<0.7$ ) are $\mathrm{P}^{2}(\mathrm{md})$, and $\mathrm{P}^{1}(\mathrm{md})$. Smaller differences in means than those of $\mathrm{P}^{2}(\mathrm{md})$ and $\mathrm{P}^{1}(\mathrm{md})$ ( $\mathrm{U}$ statistic $<0.8$ ) are shown by $\mathrm{P}^{1}(\mathrm{bl})$ and $\mathrm{P}_{1}(\mathrm{bl})$.

A single canonical discriminant function is computed since the separation of two groups is required. Summary data for this discriminant function are found in Table 3. Canonical discriminant function coefficients are derived for each variable for each function, which in their unstandardized form are useful for forming a discriminant equation of the form:

$$
D=C_{o}+C_{1} X_{1}+C_{2} X_{2}+\ldots+C_{v} X_{v}+k
$$

where $\mathrm{D}$ is the discriminant score; $\mathrm{C}$ is the unstandardized discriminant function coefficient; $\mathrm{X}$ is the value of the variable; and $\mathrm{K}$ is a constant. Unstandardized coefficients are found in Table 4. The cut-off point for the equation form is +0.03164 . The derivation of this sectioning point is discussed later. If the equation yields a score greater than this value, an individual is classified as Mongoloid based on tooth crown dimensions. If the equation yields a score below the sectioning point, the individual is classified as Caucasoid. The canonical discriminant function equation, derived from unstandardized scores, takes into account the size of each variable. Thus, the magnitude of the coefficient does not necessarily correspond to the weighting or importance of the variable in the solution.

The structure matrix (Table 5, Fig. 1), consisting of pooled within-group correlations between discriminating variables and the canonical discriminant function, demonstrates the relative importance of variables in separating population groups. The tooth crown dimensions contributing significantly to the separation between Caucasoids and Mongoloids are $\mathrm{P}^{1}$ (md and $\mathrm{bl}$ ), $\mathrm{P}^{2}(\mathrm{md})$, and $\mathrm{P}_{1}$ (md). Only these four variables possess loadings $\geq \pm 0.30$. The variables having substantial between group variation compared to within group variation, as indicated by F-ratios, correspond fairly well to the structure matrix (Table 2).

The nature of the contribution of each of the variables to separation is also indicated in Figure 1 . The majority of variables have positive correlations, while only a few have negative correlations that are of such small magnitude as to seem insignificant. Reference to the canonical discriminant functions evaluated at the group means (Caucasoid $=-1.53459$, Mongoloid $=+1.59787$ ) shows that the Mongoloid group (group 1) has a positive group centroid, while the Caucasoid group (group 2) has a negative group centroid. The loadings of each variable are interpreted in the same way. Positive loadings of variables indicate their larger size in the Mongoloid group than in the Caucasoid group and, thus, smaller sizes in the Caucasoid group than in the Mongoloid group. This is also related to the unstandardized canonical discriminant function coefficients: a positive score classifies an individual as Mongoloid based on tooth crown dimensions. A positive score is clearly then generated by larger tooth crown size dimensions than other tooth crown dimensions.

The effectiveness of the discriminant function in separating Caucasoids and Mongoloids based on tooth crown size is quantified by the success of classification. The overall success rate for correct classification is 
93.94\%. The confusion matrix (Table 6) summarizes the predicted group membership. Of the Mongoloid cases, 95.9\% (93/97) are correctly classified and 4.1\% (4/97) are incorrectly classified as Caucasoid. Exactly the same number of cases in the Caucasoid group are correctly classified, although a lower proportion than the Mongoloid group, since it is a slightly larger group $(92.1 \%$ or $93 / 101)$ than the Mongoloid group, meaning a greater number of misclassified cases $7.9 \%(8 / 101)$ than the Mongoloid group.Twice as many Caucasoid cases are misclassified as Mongoloid, compared to the converse situation. The total error rate is $6.06 \%$, since a total of 12 of the 198 cases had incorrect group predictions.

The discriminant scores on each case are proportional to the probability of classification of an individual and, again, cases with negative discriminant scores are classified as Caucasoid, and those with positive discriminant scores were classified as Mongoloid. Nine cases in the Caucasoid group (id. 56, 122, 125, $147,158,188,57,115,200$ ) and one case (id. 102) in the Mongoloid group are classified with very high probability (1.0000). The discriminant scores for these cases range from $|-3.2197|$ to $|+3.9314|$. The next highest discriminant score is $|+3.1729|$ for case 4 which is classified with a probability of 0.9999 , indicating that a discriminant score $\pm 3.1729<x< \pm 3.2197$ is required for certain classification at five significant figures.

The graphical illustration of discriminant scores (Fig. 2) shows relatively few cases misclassified in either group, though more occur in the Caucasoid group than the Mongoloid group. Interpretation of discriminant scores deserves special attention. In examining discriminant scores or any graphical representation of them the cut-off point, although very close to zero $(y=0)$, is in fact the midpoint between the group centroids, which is $(-1.53459+1.59787) / 2=+0.03164$. Thus, any discriminant score below +0.03164 is classified as Caucasoid. This explains why, in the Caucasoid group, nine cases have positive discriminant function scores and fall on the Mongoloid side of the axis, but only eight cases are actually misclassified as Mongoloid. Case 49 has a very small discriminant score $=+0.0098$, which is $<0.03164$, and is therefore classified as Caucasoid, despite appearing on the graph as Mongoloid.

Caucasoid cases appear to be classified correctly with marginally more certainty than Mongoloid cases, as indicated by the average height of columns (depicting the discriminant score). Misclassified cases in either group appear to be approximately equally spread throughout groups, that is, no particular cluster of misclassified cases. This is of interest since cases were numbered in grouped order of male and female subsamples. This is to say that neither males nor females appeared to be misclassified more than the other.

The actual success rate of $93.94 \%$ was compared with the success rates computed via the randomization procedure.

TABLE 2. Wilks Lambda (U-statistic)

\begin{tabular}{|c|c|c|c|c|}
\hline \multicolumn{2}{|c|}{ Variable } & \multirow{2}{*}{$\begin{array}{c}\text { Wilks } \\
\text { Lambda }\end{array}$} & \multirow{2}{*}{$\frac{F}{0.8101}$} & \multirow{2}{*}{$\begin{array}{l}\text { Significance }^{1} \\
0.3692\end{array}$} \\
\hline$I^{1}$ & (md) & & & \\
\hline$l^{2}$ & $(\mathrm{md})$ & 0.85090 & 34.3437 & $0.0000^{* *}$ \\
\hline UC & (md) & 0.86637 & 30.2306 & $0.0000^{\star *}$ \\
\hline$P^{\prime}$ & (md) & 0.69883 & 84.4676 & $0.0000^{* *}$ \\
\hline $\mathrm{P}^{2}$ & $(\mathrm{md})$ & 0.69676 & 85.3033 & $0.0000^{* *}$ \\
\hline $\mathbf{M}^{1}$ & (md) & 0.97214 & 5.6178 & $0.0187^{*}$ \\
\hline $\mathrm{M}^{2}$ & (md) & 0.99925 & 0.1465 & 0.7024 \\
\hline$I^{\prime}$ & (bl) & 0.99697 & 0.5965 & 0.4408 \\
\hline $\mathrm{I}^{2}$ & (bl) & 0.97252 & 5.5385 & $0.0196^{*}$ \\
\hline $\mathrm{UC}$ & (bl) & 0.99163 & 1.6547 & 0.1998 \\
\hline $\mathbf{P}^{1}$ & (bl) & 0.76879 & 58.9447 & $0.0000^{* *}$ \\
\hline $\mathrm{P}^{2}$ & (bl) & 0.96272 & 7.5904 & $0.0064^{* *}$ \\
\hline $\mathbf{M}^{1}$ & (bl) & 0.99987 & 0.0254 & 0.8734 \\
\hline $\mathrm{M}^{2}$ & (b1) & 0.99532 & 0.9207 & 0.3385 \\
\hline$I_{1}$ & $(\mathrm{md})$ & 0.90469 & 20.6493 & $0.0000 * *$ \\
\hline $\mathrm{I}_{2}$ & (md) & 0.95330 & 9.6019 & $0.0022^{*}$ \\
\hline LC & $(\mathrm{md})$ & 0.88633 & 25.1360 & $0.0000^{\star *}$ \\
\hline$P_{1}$ & (md) & 0.78348 & 54.1670 & $0.0000^{\star * \star}$ \\
\hline$P_{2}$ & (md) & 0.89925 & 21.9588 & $0.0000^{* *}$ \\
\hline$M_{1}$ & (md) & 0.89836 & 22.1759 & $0.0000^{* *}$ \\
\hline $\mathrm{M}_{2}$ & (md) & 0.99314 & 1.3548 & 0.2459 \\
\hline$I_{1}$ & (bl) & 0.95779 & 8.6367 & $0.0037^{\star * *}$ \\
\hline $\mathrm{I}_{2}$ & (bl) & 0.95779 & 0.2223 & 0.6378 \\
\hline $\mathrm{LC}$ & (bl) & 0.99924 & 0.1495 & 0.6995 \\
\hline$P_{1}$ & (bl) & 0.85325 & 33.7093 & $0.0000^{* *}$ \\
\hline $\mathrm{P}_{2}$ & (bl) & 0.99191 & 1.5994 & 0.2075 \\
\hline$M_{1}$ & (bl) & 0.93227 & 14.2396 & $0.0002^{\star \star}$ \\
\hline $\mathrm{M}_{2}$ & (bl) & 0.97299 & 5.4411 & $0.0207^{*}$ \\
\hline
\end{tabular}


OdONTOMETRIC VARIATION IN HUMAN POPULATIONS

TABLE 3. DFA summary statistics and significance tests.

\begin{tabular}{|c|c|c|c|c|c|c|c|c|c|}
\hline Function & Eigenvalue & $\begin{array}{c}\% \\
\text { of Variance }\end{array}$ & $\begin{array}{c}\text { Cumulative } \\
\%\end{array}$ & $\begin{array}{l}\text { Canonical } \\
\text { Correlation }\end{array}$ & $\begin{array}{c}\text { After } \\
\text { function }\end{array}$ & $\begin{array}{c}\text { Wilks } \\
\text { lambda }\end{array}$ & Chi-square & $\mathrm{df}$ & Significance \\
\hline & & & & : & 0 & 0.287597 & 226.808 & 28 & $0.0000^{* *}$ \\
\hline 1 & 2.4771 & 100.0 & 100.0 & 0.844 & & & & & \\
\hline
\end{tabular}

Ninety-nine percent confidence limits were $57.6 \%-73.7 \%$. Since the actual success rate falls well outside these confidence limits, the results of the multivariate analysis were significant at $\mathrm{p}<0.001$.

\section{Summed Diameters and Tooth Crown Areas}

In maxillary and mandibular teeth, summed mesiodistal diameters are significantly larger in Mongoloids compared to Caucasoids for all tooth regions. The greatest differences $(\mathrm{p}<0.001)$ for mesiodistal diameters in the maxilla exist for the canine, followed by the postcanine teeth and then incisor teeth. In the mandible postcanine teeth have greater differences between groups than the canine and incisors, respectively. Differences between groups in summed mesiodistal diameters are greater in the maxilla than the mandible. In the buccolingual dimension, highly significant differences $(p<0.001)$ between Caucasoids and Mongoloids are apparent in the posterior teeth for both maxillary and mandibular teeth. Significant differences $(p<0.05)$ are also shown for the canine, followed by the incisors. The summed buccolingual diameters are significantly different between groups for the postcanine group only, where Mongoloids are larger than Caucasoids. Results are found in Table 7.

In areal dimensions ( $\mathrm{md} \mathrm{x} \mathrm{bl}$ ) of the incisor group, canine and postcanine group, the maxillary variables again show greater differences than mandibular variables. In the maxilla, the crown area of incisors, the canine, and postcanine teeth are all significantly larger in Mongoloids compared with Caucasoids $(p<0.05)$. In the mandible, only the areas of the canine and the postcanine teeth are significantly different between groups, with Mongoloids again larger than Caucasoids. Results are found in Table 7.

\section{DISCUSSION}

Results of statistical analyses indicate greater differences between the dentition of Mongoloids and Caucasoids in univariate analyses compared to the multivariate analyses. This is not surprising, since univariate statistics are known to overestimate significant differences in treating each variable individually, and fail to consider the correlations between variables. Many investigators (e.g.., Oxnard, 1968; Potter, 1972) have cautioned against relying solely on univariate statistics, although studies utilizing only these methods persist in the literature.

Eighteen tooth size variables are identified by Student's $t$-tests as being significantly larger in Mongoloids compared to Caucasoids, whereas canonical variate analysis identified four variables as significant discriminators between groups. Larger dimensions of Mongoloid teeth compared to Caucasoid teeth have previously been reported in the deciduous dentition (Lavelle, 1970). Variables ranked highest from 1 to 14 in the structure matrix were highly significantly different $(p<0.01)$ according to $t$-tests, while variables ranked 15 to 18 in the structure matrix were also consistently significant but to a lesser extent $(p<0.05)$ than the other variables in $t$-tests. The small discrepancy may be explained by the fairly arbitrary cut-off points set for the univariate analyses. Those values falling just outside significance levels are virtually identical to those falling just within the level of significance. Smith (1999) takes the approach that those variables marginally insignificant in the univariate analyses, but significantly contributing to the separation in multivariate analysis, could most probably be interpreted as truly contributing to the separation between samples. Although a conservative approach is to declare non-significance at a set cut-off point, the biological implications of marginally significant variables can possibly be ignored in this way. 
A larger size of some premolar dimensions is evident in Mongoloids compared to Caucasoids, implicating the premolars in being particularly effective for separation of these groups. However, that only select premolar dimensions are involved in the remarkable separation between Mongoloids and Caucasoids based on simple tooth crown diameters, is obvious. Even so, additional premolar dimensions feature strong correlations with the discriminant function. $\mathrm{P}_{1}(\mathrm{bl})$ is fairly strongly correlated with the discriminant function $(0.26350)$, as is $P_{2}$ (md) (correlation with discriminant function $=0.21267$ ). Consideration of these two variables, in turn, gives an impression of tooth crown areas of $\mathrm{P}^{1}$ and $\mathrm{P}_{1}$ being larger in Mongoloids than Caucasoids, and mesiodistal diameters of $\mathrm{P}^{2}$ and $\mathrm{P}_{2}$ also larger in Mongoloids than Caucasoids. Curiously, the buccolingual dimensions of $\mathrm{P}^{2}$ and $\mathrm{P}_{2}$ are fairly weakly correlated with the discriminant function and are certainly non-significant, especially the mandibular component $\left(\mathrm{P}^{2}=0.12504 ; \mathrm{P} 2=0.05739\right)$. These latter two variables cannot be included in the concept of larger premolar dimensions in Mongoloids than in Caucasoids. These results are interesting in showing the relatively greater contribution of P1 over P2, generally, to separation of groups, as well as greater contribution of mesiodistal over buccolingual diameters. The $P_{2}$ is known to be more variable in form than $P_{1}$ (Carlsen and Alexandersen, 1994). Although humans have lost the true upper and lower first and second premolars, reduction takes place from the most distal one, mesially in both jaws or only in the lower jaw (Grahnén, 1962).

Briefly, similar results are obtained for CVA and DFA on tooth crown measurements from the right hand side of the dental arch. Identical premolar dimensions are significant separators of groups, although the first two variables are reversed in order: $\mathrm{P}^{1}(\mathrm{md}), \mathrm{P}^{2}(\mathrm{md}), \mathrm{P}^{1}(\mathrm{bl})$, and $\mathrm{P}_{1}(\mathrm{md})$. In addition, the maxillary canine $(\mathrm{UC}, \mathrm{md})$ and $\mathrm{P}_{1}(\mathrm{bl})$ are also significant contributors to separation. As in analysis of the left side measurements, $\mathrm{P}_{2}(\mathrm{md})$ is just below the threshold for significant contribution to separation, while $\mathrm{P}_{2}(\mathrm{bl})$ is very weakly correlated with the discriminant function. In spite of the asymmetry detected in initial paired t-tests, little overall effect on multivariate analyses is seen.

Possibly, the multivariate analysis has been unduly affected by the presence of outliers, which may distort the results in any direction. In preliminary screening and examination of the data, not a single multivariate outlier was identified. Univariate screening of the data was conducted. For the sake of brevity boxplots and z-scores are not provided but are summarized as follows: for the cases misclassified by DFA, two individuals in the Caucasoid group (id. 45 and 112) had some tooth size dimensions identified as univariate outliers through examination of boxplots. Two cases in the Mongoloid group (id. 48 and 139) had variables identified as univariate outliers through boxplots, and one case (id. 60) had variables identified as an univariate outlier based on boxplots and z-scores. Outliers can occur in any direction.
TABLE 4.Unstandardized discriminant function coefficients.

Unstandardized

Discriminant

Function

Variable Coefficients

\begin{tabular}{|c|c|c|}
\hline$I^{1}$ & $(\mathrm{md})$ & -0.7577334 \\
\hline $\mathrm{I}^{2}$ & (md) & 0.3853306 \\
\hline $\mathrm{UC}$ & (md) & -0.0850442 \\
\hline $\mathrm{P}^{\prime}$ & (md) & 0.4662808 \\
\hline $\mathrm{P}^{2}$ & (md) & 2.1581784 \\
\hline $\mathbf{M}^{1}$ & (md) & -0.3218897 \\
\hline $\mathrm{M}^{2}$ & (md) & -0.9167015 \\
\hline $\mathrm{I}^{\prime}$ & (bl) & 0.2282310 \\
\hline $\mathrm{I}^{2}$ & (bl) & 0.4667222 \\
\hline $\mathrm{UC}$ & (bl) & -0.0767832 \\
\hline $\mathrm{P}^{1}$ & (bl) & 1.3962831 \\
\hline $\mathrm{P}^{2}$ & (b1) & -1.1856690 \\
\hline $\mathbf{M}^{1}$ & (bl) & -0.2368220 \\
\hline $\mathbf{M}^{2}$ & (bl) & -0.1252859 \\
\hline$I_{1}$ & $(\mathrm{md})$ & 0.4540023 \\
\hline $\mathrm{I}^{2}$ & (md) & -0.1307232 \\
\hline $\mathrm{LC}$ & $(\mathrm{md})$ & 0.2121910 \\
\hline$P_{1}$ & $(\mathrm{md})$ & 0.1648197 \\
\hline $\mathrm{P}_{2}$ & $(\mathrm{md})$ & -0.2242924 \\
\hline $\mathbf{M}_{1}$ & (md) & 0.9447300 \\
\hline $\mathrm{M}_{2}$ & (md) & -0.3020549 \\
\hline$I_{1}$ & (bl) & -1.6685050 \\
\hline $\mathrm{I}_{2}$ & (bl) & 0.6123724 \\
\hline $\mathrm{LC}$ & (bl) & -0.3871803 \\
\hline$P_{1}$ & (bl) & 0.5232794 \\
\hline $\mathrm{P}_{2}$ & (bl) & -0.3686911 \\
\hline $\mathrm{M}_{\mathrm{i}}$ & (bl) & -0.1814727 \\
\hline $\mathrm{M}_{2}$ & (bl) & 0.3608481 \\
\hline
\end{tabular}

(constant)

$-6.8177253$ 
TABLE 5. Pooled within-groups correlations between discriminating variables (DV) and the discriminant function $(D F)$

Within-groups correlation between

Variable DV and DF

$I^{\prime} \quad(\mathrm{md}) \quad 0.04085$

$\mathrm{I}^{2} \quad(\mathrm{md}) \quad 0.26597$

UC (md) 0.24953

$\mathrm{P}^{\mathrm{l}}$ (md) 0.41711

$\mathrm{P}^{2} \quad$ (md) 0.41916

$\mathrm{M}^{1}$ (md) $\quad 0.10757$

$\mathrm{M}^{2} \quad(\mathrm{md}) \quad-0.01737$

$\mathrm{I}^{1} \quad$ (bl) $\quad 0.03505$

$\mathrm{I}^{2} \quad(\mathrm{bl}) \quad 0.10681$

UC (bl) $\quad 0.05838$

$\mathrm{P}^{\prime} \quad$ (bl) $\quad 0.34844$

$\mathrm{P}^{2}$ (bl) $\quad 0.12504$

$\mathrm{M}^{\prime}$ (bl) $\quad 0.00724$

$\mathrm{M}^{2}$ (bl) $\quad 0.04355$

$I_{1} \quad(\mathrm{md}) \quad 0.20623$

$\mathrm{I}^{2}$ (md) $\quad 0.14063$

LC （md） 0.22754

$\mathrm{P}_{1}$ (md) $\quad 0.33402$

$\mathrm{P}_{2}$ (md) $\quad 0.21267$

$\mathrm{M}_{1} \quad$ (md) $\quad 0.21372$

$\mathrm{M}_{2}$ (md) $\quad 0.05283$

$\mathrm{I}_{1} \quad$ (bl) $\quad-0.13338$

$\mathrm{I}_{2}$ (bl) $\quad-0.02140$

LC (bl) $\quad-0.01755$

$\mathrm{P}_{1} \quad$ (bl) $\quad 0.26350$

$\mathrm{P}_{2} \quad$ (bl) $\quad 0.05739$

$\mathrm{M}_{1}$ (bl) $\quad 0.17126$

$\mathrm{M}_{2}$ (bl) $\quad 0.10586$
That some of the cases correctly classified in DFA are also found to be outliers is not surprising. A few cases that were classified with a probability of 1.0000 in the Caucasoid group, were also identified as univariate outliers by boxplots (id. 56, 122, 200).

Possibly, the premolar dimensions that are larger than others, particularly in the buccolingual diameter, may have resulted from additional cuspules analogous to Carabelli's cusp on the maxillary molars. However, premolars appear to have arisen from the reduction of molars, via reduction of the protocone, and suppression of the lingual cingulum which forms the hypocone and Carabelli's cusp (Korenhof, 1960). Therefore, to find these kinds of features on the premolars is highly unlikely.

Based on mean crown diameters, Moorrees (1957) has reported no differences in the size of premolars of Mongoloids and Caucasoids. Lavelle (1973) also reports little discrimination of Mongoloids and Caucasoids based on maxillary premolar dimensions, including mesiodistal and buccolingual crown diameters, cusp heights, and intercusp distances. When maxillary molar measurements were added to the canonical analysis, the discrimination improved. This outcome is not surprising since discernibility between groups (e.g., subpopulations, species, suborders) is increased as an increased number of characteristics of teeth are measured and analyzed (Stern and Skobe, 1985). If mesiodistal and buccolingual measurements only were utilized, different results again would probably be obtained. The evidence for this rests with the report of conflicting discriminant functions following the use of different sets of measurements for the canine teeth of humans and chimpanzees (Bronowski and Long, 1951; Yates and Healey, 1951). As far as the author is aware, the same 28 variables utilized in the present study have not been applied to the same population groups to create a DF, precluding any direct comparisons.

\section{"Within" Premolar Differences}

While the present research presents evidence of discernible differences between contemporary Caucasoids and Mongoloids in the gross crown size of premolars with respect to the remaining dentition, differences are reported within the premolars, themselves. This finding supports the notion that additional significant information can be gained from measurements of gross dental morphology (Moss et al., 1967; Biggerstaff, 1969a; Wood and Abbott, 1983; Lavelle, 1984). The investigation of "within-tooth" differences of the postcanine dentition was established by Biggerstaff (1969a), who identified definable tooth crown landmarks, as well as a reliable and accurate method to record them (Biggerstaff, 1969b).

Corruccini $(1977 \mathrm{~b} ; 1978)$ demonstrates substantial discrimination between humans and extant pongids based on a single premolar tooth. Principal components analysis of ten landmarks to describe the crown component variation of $\mathrm{P}_{2}$ and canonical analysis of seven landmarks quantifying the crown variation of $\mathrm{P}^{1}$ produced similar results. Observed differences are attributed to functional observations. 
Human population differences in metric crown profiles of premolars are reported (Lavelle, 1978, 1984). Canonical analyses utilizing mandibular premolars provide better separation of groups than analyses involving maxillary counterparts (Lavelle, 1978). First and second premolar measurements are more effective separators than second premolar measurements alone, which in turn are notably more effective than maxillary measurements alone, the least effective separators. These results are summarized as follows:

$$
\mathrm{P}_{1}+\mathrm{P}_{2}>\mathrm{P}_{2}>\mathrm{P}^{1}+\mathrm{P}^{2} \geq \mathrm{P}_{1}>\mathrm{P}^{1}
$$

These results are intriguing, since we find the overall dimensions of maxillary premolars to be better discriminators than mandibular premolars, with first premolars contributing more than second premolars. In effect, overall dimensions and within-tooth differences of premolars seem to provide conflicting results.

A new approach to quantitative assessment of teeth has been suggested (Morris, 1981), and involves angular measurements to appraise anterior buccolingual compression and posterior expansion of $\mathrm{P}^{1}$. Although the observed differences between Caucasoids and Mongoloids are inconsistent regarding angular measurements, refinement of the technique and incorporation with a suite of crown measurements might prove rewarding. Interestingly, tooth size is apparently not the reason for angular differences, since smalltoothed urban South African Indians showed larger angles than the relatively larger-toothed Africans (Central Sotho) (Morris, 1981), implicating proportional differences within the tooth.

Series of measurements of the occlusal surfaces of tooth crowns have resolved some of the objections to traditional odontometrics. While the information is valuable and interesting, we must be cautious not to limit the scope of odontometrics too greatly. Although not yet a problem, in foresight we propose that traditional dental measurements be retained. Prior to the introduction of detailed crown measurements of the occlusal surface, "...descriptive and mensurational studies of the dentition occupy a major role in the armamentarium of anthropology, comparative anatomy, and palaeontology" (Moss and Chase, 1966). With access to the enormous body of conventional odontometric data collected since the inception of dental mensuration, investigators are offered an unparalleled body of data available for comparative purposes.

\section{Summed Tooth Diameters}

Summed mesiodistal diameters are significantly larger in Mongoloids compared to Caucasoids more often than summed buccolingual diameters. This result is expected since for Student's $t$-tests of individual diameters, a greater number of mesiodistal diameters are significantly different between groups, than buccolingual diameters. Summed buccolingual diameters were significantly larger in Mongoloids than Caucasoids for the postcanine teeth only. In fact, Caucasoids are larger than Mongoloids in the summed buccolingual diameters of the mandibular incisors and mandibular canine. Although neither comparisons are significant, the incisors approach significance so closely as to warrant special, albeit brief, discussion here. Perhaps this observation is related to a compensatory mechanism of some nature. The high frequencies of shovel-shaped incisors in Mongoloids (Hrdlicka, 1920; Dahlberg, 1951; Hanihara, 1968) may function to strengthen the anterior tooth crowns in the way that engineering data identify the I-beam as structurally superior to a solid oblong-shaped girder. Perhaps, in the absence of genetic information to code for shovelshaped incisors, Caucasoids have developed thicker anterior teeth than those of Mongoloids to provide the required strength. We stress that the incidence of shovel-shaped incisors has not been assessed in this sample, and we wish merely to offer a possible explanation for our results. 
Table 7. Univariate differences (Student's t-test) between Mongoloids and Caucasoids in summed mesiodistal diameters, buccolingual diameters, and crown areas of incisors, canines, and post-canine teeth.

\begin{tabular}{|c|c|c|c|c|c|c|}
\hline Variable & & $\bar{x} \mathbf{M}-\bar{x} C^{l}$ & $\begin{array}{l}\text { average } \\
\text { difference/tooth }\end{array}$ & $\begin{array}{l}\text { SE } \\
\text { of diffrence }\end{array}$ & $\mathrm{t}$ & $\mathrm{p}(2 \text { tail })^{2}$ \\
\hline $\mathrm{I}^{1}+\mathrm{I}^{2}$ & (md) & 0.5465 & 0.2733 & 0.155 & 3.53 & $0.001 * *$ \\
\hline $\mathrm{UC}$ & (md) & 0.3513 & 0.3513 & 0.066 & 5.30 & $0.000 * *$ \\
\hline $\mathbf{P}^{1}+\mathrm{P}^{2}+\mathbf{M}^{1}+\mathbf{M}^{2}$ & (md) & 1.1200 & 0.2800 & 0.278 & 4.03 & $0.000^{\star \star}$ \\
\hline$I_{1}+I_{2}$ & (md) & 0.3935 & 0.1968 & 0.105 & 3.76 & $0.000 * *$ \\
\hline LC & (md) & 0.3030 & 0.3030 & 0.062 & 4.88 & $0.000 * *$ \\
\hline$P_{1}+P_{2}+M_{1}+M_{2}$ & (md) & 1.2503 & 0.3126 & 0.305 & 4.10 & $0.000 * *$ \\
\hline$I^{1}+I^{2}$ & (bl) & 0.2321 & 0.1161 & 0.162 & 1.43 & 0.154 \\
\hline $\mathrm{UC}$ & (bl) & 0.1168 & 0.0068 & 0.095 & 1.22 & 0.223 \\
\hline $\mathbf{P}^{1}+\mathrm{P}^{2+} \mathbf{M}^{1}+\mathbf{M}^{2}$ & (bl) & 0.9112 & 0.2278 & 0.380 & 2.40 & $0.018^{*}$ \\
\hline$I_{1}+I_{2}$ & (bl) & -0.2363 & -0.1182 & 0.120 & -1.97 & 0.051 \\
\hline LC & (bl) & -0.0269 & -0.0269 & 0.083 & -0.32 & 0.747 \\
\hline$P_{1}+P_{2}+M_{1}+M_{2}$ & (bl) & 0.8709 & 0.2177 & 0.318 & 2.74 & $0.007^{* *}$ \\
\hline $\mathbf{I}^{1}+\mathbf{I}^{2}$ & $(\mathrm{mdxbl})$ & 5.1995 & 2.5998 & 2.168 & 2.40 & $0.018^{\star}$ \\
\hline UC & $(\mathrm{mdxbl})$ & 3.8404 & 0.8404 & 1.143 & 3.36 & 0.001 ** \\
\hline $\mathrm{P}^{1}+\mathrm{P}^{2+} \mathrm{M}^{1}+\mathrm{M}^{2}$ & $(\mathrm{mdxbl})$ & 17.5458 & 4.3865 & 6.161 & 2.85 & $0.005^{* *}$ \\
\hline $\mathbf{I}_{1}+\mathbf{I}_{2}$ & $(\mathrm{mdxbl})$ & 1.4447 & 0.7224 & 1.236 & 1.17 & 0.244 \\
\hline LC & $(\mathrm{mdxbl})$ & 2.0109 & 2.0109 & 0.936 & 2.15 & $0.033^{*}$ \\
\hline$P_{1}+P_{2}+M_{1}+M_{2}$ & $(\mathrm{mdxbl})$ & 19.8457 & 4.9614 & 5.620 & 3.53 & $0.001^{* *}$ \\
\hline
\end{tabular}

${ }^{\mathrm{l}} \mathrm{M}$ is Mongoloid; $\mathrm{C}$ is Caucasoid; ${ }^{2 *}(\mathrm{P}<0.05) .{ }^{* *}(\mathrm{p}<0.01)$

\section{Postcanine Area}

The computation of tooth crown areas indicates that the postcanine teeth, as a unit and on a per-tooth basis, exhibit the greatest areal differences for both maxillary and mandibular dimensions between Mongoloids and Caucasoids. This is expected in light of the convincing differences in premolars between groups. The method of calculating crown area in the molar region overestimates the actual occlusal area (Wood and Engelman, 1988). Also, we define mesiodistal diameter as the distance between the interproximal contact points, rather than the maximum length of the crown, probably resulting in a smaller area than might normally be estimated. These two considerations act in opposing directions towards a cancelling-out effect. Although the extent of each effect not known, it is likely to differ according to tooth type since different ratios of length to breadth exist across tooth classes. Even though the crown area measurements obtained here may not be as accurate as is achievable with today's technological aids, they serve sufficiently for comparative purposes across the dentition.

The function of a larger postcanine area in humans than in other species has not been specifically addressed and remains unclear, although a brief discussion follows. Clearly, the main function of the teeth in humans is as a food-processing device. In order to glean the significance of a relatively larger postcanine tooth size area, one has to understand the function of the postcanine tooth. The single most important oral 


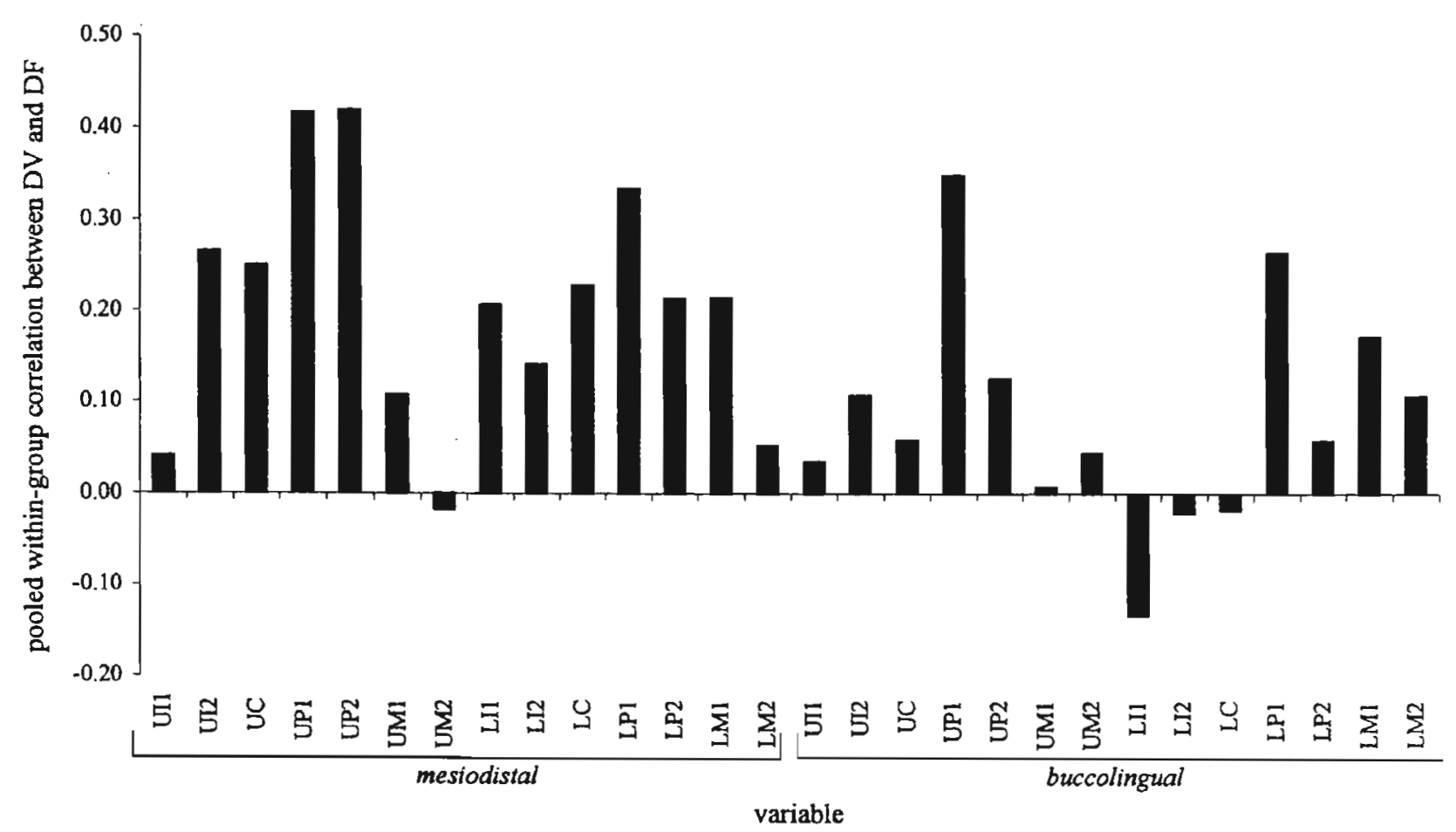

Fig. 1. Structure matrix. $U=$ upper. $L=$ lower.

variable in human studies that influences the rate of food breakdown is the postcanine tooth size (Manly, 1951; Helkimo et al., 1978; Kayser, 1980).

Several studies have attempted to correlate the size of postcanine teeth with diet (e.g., folivore, frugivore, omnivore) in primates (e.g., Kay, 1975; Goldstein et al., 1978; Gingerich et al., 1982). Lucas et al.(1986) have suggested that in anthropoid primates, natural selection should favor a greater buccolingual width than mesiodistal width of the postcanine teeth, since food particles form a ball or bolus in the mouth which can then be distributed to the teeth en masse by lateral movements of the tongue. Lateral movements of the tongue are the most likely to distribute the bolus of food to the postcanine teeth, where the chance of breaking food particles is improved. Chemically sealed non-sticky food particles, such as vegetable matter, demand a large postcanine tooth row in which tooth length is as important as tooth width, and no tooth is necessarily larger than any other. In contrast, high volumes of large and/or sticky food particles require a small wide tooth row with large central teeth in the postcanine row (Lucas et al., 1986). Possibly, the differences elucidated in this study are a result of dietary differences, but this certainly requires further research. Although an original assessment of diet was attempted in our research design, the information was too incomplete and non-specific to attempt any analysis. Generally, though, the dietary composition of the populations in Sydney is rather similar between populations due to the diverse and multicultural nature of this large city. Traditional Asian diets are less likely to exist than in people's homeland. While, the adaptation of teeth to the mechanical properties of food has been emphasized (e.g., Maier, 1984; Lucas et al., 1986), just how far the analysis of diet can explain tooth form is unclear, since this approach fails to consider the design of structural supports of the teeth, jaws, and face to accommodate the additional effects of bite forces (Lucas et al., 1986).

\section{P1 vs P2}

Examining the relationship between $\mathrm{P} 1$ and $\mathrm{P} 2$ is valuable. According to mean values, the first premolar is larger than the second premolar more frequently in Mongoloids compared with Caucasoids, perhaps 
emphasizing its discriminatory power. In the maxillary premolars, $\mathrm{P} 1>\mathrm{P} 2$ occurs in the mesiodistal diameter of both Mongoloids and Caucasoids. In the buccolingual diameter of the maxillary premolars, P1>P2 appears in Mongoloids only. In Caucasoids the $\mathrm{P} 1<\mathrm{P} 2$ is seen. In the mesiodistal diameter of the mandibular premolars, the first premolar is marginally larger than the second premolar in Mongoloids (P1 $\geq \mathrm{P} 2)$, and the second premolar is larger than the first in Caucasoids $(\mathrm{P} 1<\mathrm{P} 2)$. In the buccolingual diameter of the mandibular premolars $\mathrm{P} 1<\mathrm{P} 2$ in both Mongoloids and Caucasoids. Preliminary unpublished analyses show that all measurements of $\mathrm{P} 1$ and $\mathrm{P} 2$ are significantly different from each other within population groups, except the mandibular mesiodistal diameter of Mongoloids. Differences between the premolars were also examined with respect to the crown areas ( $\mathrm{md} \mathrm{x} \mathrm{bl}$ ). Equivalent results for Caucasoids and Mongoloids are observed in the maxilla and mandible, with maxillary premolars displaying $\mathrm{P} 1>\mathrm{P} 2$, with Mongoloids showing $\mathrm{P} 1>>\mathrm{P} 2$. In mandibular premolars the trend is reversed, with $\mathrm{P} 1<\mathrm{P} 2$, with Caucasoids $(\mathrm{P} 1<<\mathrm{P} 2)$ showing a more marked difference in areal dimensions of P1 and P2 than Mongoloids. All comparisons are highly significant $(\mathrm{p}<0.001)$. Clearly the buccolingual diameter strongly influences the trend observed in areal measurements of the mandibular premolars.

Swindler (1976) records a trend in the relative size of the crown areas of the two maxillary premolars in primates, with the mean values of P3 crown being consistently larger than those of the equivalent P4. Robinson (1956) comments on the relative homomorphy among hominid maxillary premolars, stating that "there is consequently not a clear distinction between prehominid (i.e., australopithecine) and euhominid (i.e., Homo) maxillary premolars". Hence it appears that observations made for early hominid premolars can be applied to the human situation. Although both population groups display the trend of occlusal area $\mathrm{P} 1>\mathrm{P} 2$ in the maxillary premolars, the effect is more marked in the Mongoloid dentition. Wood and Engelman (1988) conclude that in finding P3>P4 is most likely to be a primitive trait of maxillary premolars for the African ape/human clade. However, Hillson (1996) states that whist usually maxillary P1 $>$ P2 in humans, australopithecine (especially Paranthropus) premolars show the reverse trend. Gregory (1922) points out that the premolars of humans show a considerable range in size, and large premolars are regarded as primitive and small ones as recent forms. We are wary of making conclusions relating to this sample.

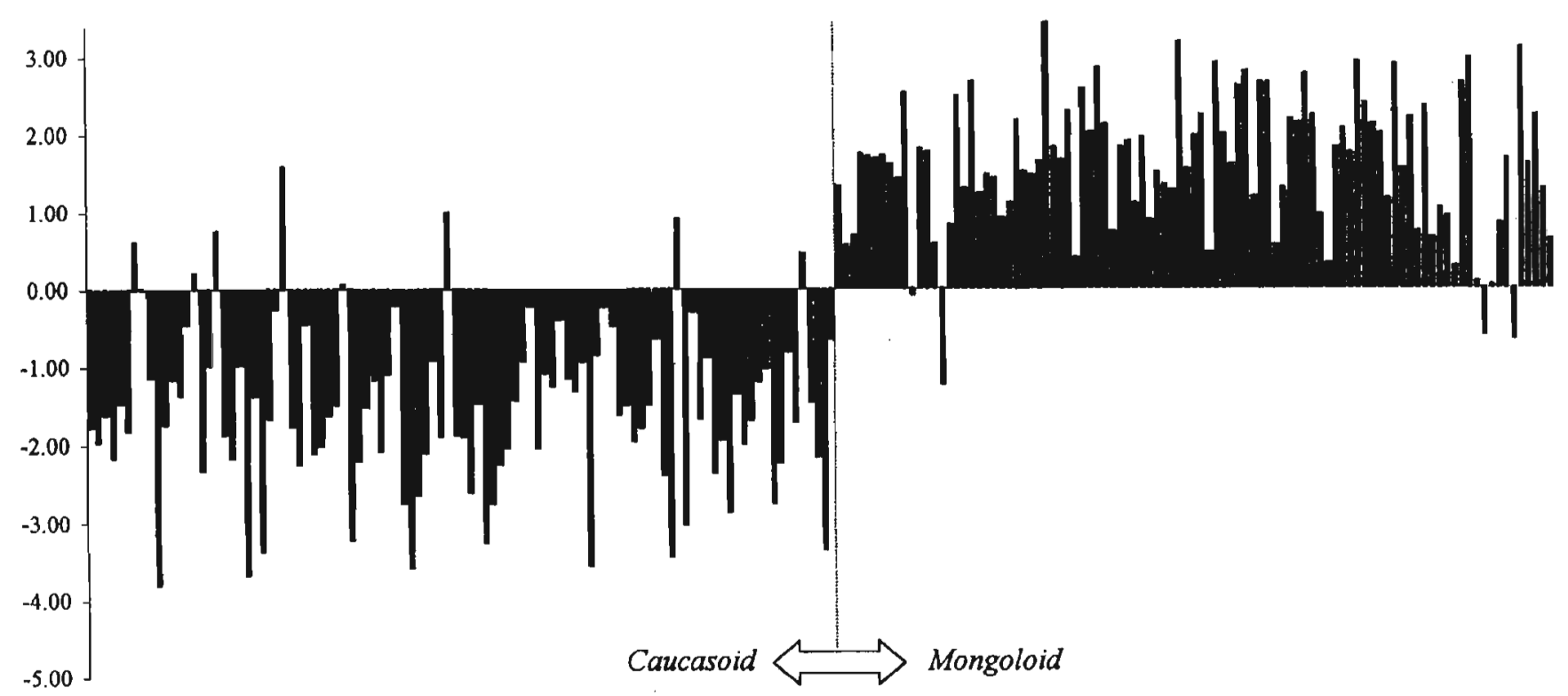

Fig. 2. Discriminant Scores 


\section{CONCLUSIONS}

We wish to emphasize the successful separation of two contemporary populations based on simple tooth crown diameters combined with multivariate statistical techniques. The discrimination of the major groups living in Sydney, the largest city in Australia, has important implications for identification of heavily decomposed and skeletal remains in the forensic setting. Successful application of these results is likely, although further exploration is required prior to the implementation of this new knowledge. The allocation or assignment of individuals should be considered separately and independently to discrimination or classification (Campbell, 1984; Kieser and Groeneveld, 1990). Examination of the literature illustrates the inappropriate use of discriminant analysis in allocating an individual to group membership. These issues have been discussed, but continue to be largely ignored. Our results, as they relate to allocation, will be reported in a later study. We are presently concentrating on developing the statistical means to achieve these analyses, based on the work of Campbell (1984) and Kieser and Groeneveld (1990). Meanwhile, we recommend that all available criteria be utilized in combination for the problem of determining population affinity.

\section{ACKNOWLEDGEMENTS}

The authors wish to kindly thank Professor Richard V.S. Wright for his assistance with data analysis and use of the statistical computer program MV NUTSHELL, without which this study would not have been possible. The primary author wishes to thank Jules Kieser, Simon Hillson, and Christopher King for valuable discussions relating to the work, as well as three anonymous reviewers. We also wish to thank the following individuals and institutions for their assistance: Professor Cedric Shorey, Head of Department of Anatomy and Histology at the University of Sydney; Professor Cyril Thomas, Dr. Gregory A. Doran, and the United Dental Hospital, Surry Hills, Sydney. This research design has been approved by the Human Ethics Committee, University of Sydney.

\section{FOOTNOTES}

${ }^{1}$ Full descriptive statistics are available on request to the authors.

${ }^{2}$ Human premolars are referred to as P3 and P4 in paleontological termonology, but P1 and P2 are used mainly here.

\section{LITERATURE CITED}

Barrett MJ, Brown T, Arato G, Ozols IV. 1964. Dental observations on Australian aborigines: Buccolingual crown diameters of deciduous and permanent teeth.Aust Dent J 9:280-285.

Barrett MJ, Brown T, Macdonald MR. 1963. Dental observations on Australian aborigines: Mesiodistal crown diameters of permanent teeth.Aust Dent J 8: 150-155.

Biggerstaff RH. 1969a. The basal area of the posterior tooth crown components: the assessment of within tooth variations of premolars and molars. Arn J Phys Anthropol 31:163-170.

Biggerstaff RH. 1969b. Electronic methods for the analysis of the human post-canine dentition. Am J Phys Anthropol $31: 235-242$.

Bronowski J, Long WM. 1951. Statistical methods in anthropology. Nature 168:794.

Brothwell DR. 1967. Some problems and objectives related to the study of dental variation in human populations. J Dent Res 46:938-941.

Butler PM. 1939. Studies of the mammalian dentition: differentiation of the postcanine dentition. Proceedings of the Zoological Society, London 109: 1-36.

Campbell NA. 1984. Some aspects of allocation and discrimination. In: Van Vark GN, Howells WW. editors. Multivariate Statistical Methods in.Physical Anthropology. Dordrecht: Reidl. p 177-192.

Carbonell VM. 1963. Variations in the frequency of shovel-shaped incisors in different populations. In: Brothwell DR, editor. Dental Anthropology. Oxford: Pergamon Press. p 211-234.

Carisen O, Alexandersen V. 1994. Mandibular premolar differentiation. Scandinavian J Dent Res 102:81-87.

Corruccini RS. 1977a. Crown component variation in Hominoid lower third molars. Z Morphol Anthropol 68:14-25. 


\section{ODONTOMETRIC VARIATION IN HUMAN POPULATIONS}

Corruccini RS. 1977b. Crown component variation in the hominoid lower second premolar. J Dent Res 56:1093-1096.

Corruccini RS. 1978. Crown component variation in hominoid upper first premolars. Arch Oral Biol 23:494-494.

Dahlberg AA. 1945. The changing dentition of man. J Am Dent Assoc 32:676-690.

Dahlberg AA. 1951. The dentition of the American Indian. In: Laughlin WS, editor. The Physical Anthropology of the American Indian. New York: Viking Fund. p 138-176.

Dahlberg AA. 1956. Materials for the establishment of tooth characteristics, attributes, and techniques in morphological studies of the dentition. University of Chicago: Zoller Laboratory of Dental Anthropology.

Dahlberg G. 1940. Statistical Methods for Medical and Biological Students. London: George Allen and Unwin.

Gingerich PD, Smith BH, Rosenberg K. 1982. Allometric scaling in the dentition of primates and predictions of body weight from both size in fossils. Am J Phys Anthropol 58:81-100.

Goldstein S. Post D, Melnick D. 1978. An analysis of cercopithecoid odontometrics. I. The scaling of the maxillary dentition. Am J Phys Anthropol 49:517-532.

Goose DH. 1963. Dental measurements: An assessment of its value in anthropological studies. In: Brothwell DR, editor. Dental Anthropology. Oxford: Pergamon Press. p 125-148.

Goose DH. 1967. Preliminary study of tooth size in families. J Dent Res 46:959-962.

Grahnén H. 1962. Hereditary factors in relation to dental caries and congenitally missing teeth. In: Witkop Jr CJ, editor. Genetics and Dental Health. New York: McGraw-Hill. p 194-204.

Gregory WK. 1922. The Origin and Evolution of the Human Dentition. Baltimore: Williams and Wilkins Company.

Hanihara K. 1961. Criteria for classification of crown characters of the human deciduous dentition. J Anthropol Soc Nippon 69:27-45.

Hanihara K. 1967. Racial characteristics in the dentition. J Dent Res 46:923-926.

Hanihara K. 1968. Mongoloid dental complex in the permanent dentition. Proceedings of the VIIIth Congress of Anthropological and Ethnological Sciences S-2 $1: 298-300$.

Hanihara K. 1978. Differences in sexual dimorphism in dental morphology among several human populations. In: Butler PM, Joysey KA, editors. Development, Function and Evolution of Teeth. London: Academic Press. p 127-134.

Harris EF, Rathbun TA. 1991. Ethnic differences in the apportionment of tooth sizes. In: Kelley MA, Larsen CS, editors. Advances in Dental Anthropology. New York: Wiley-Liss. p 121-142.

Helkimo E, Carlsson GE, Helkimo M. 1978. Chewing efficiency and state of dentition. Acta Odontol Scandinav 36:3341. Hillson S. 1996. Dental Anthropology. Cambridge: Cambridge University Press.

Hrdlička A. 1920. Shovel-shaped teeth. Am J Phys Anthropol 3:429-465.

Hunter WS, Priest WR. 1960. Errors and discrepancies in measurement of tooth size. J Dent Res 39:405-414.

Kay RF. 1975. Functional adaptations of primate molar teeth. Am J Phys Anthropol 43: 195-216.

Kayser A. 1980. Shortened dental arches and oral function. J Oral Rehab 8:457-462.

Kieser JA. 1990. Human Adult Odontometrics: The Study of Variation in Adult Tooth Size. Cambridge: Cambridge University Press.

Kieser JA, Groeneveld HT. 1987. Tooth size and arcadal length correlates in man. Int J Anthropol 2:3746.

Kieser JA, Groeneveld HT. 1990. Aspects of the human cranial base: A multivariate approach. In: Sperber GH, editor.

From Apes to Angels: Essays in Anthropology. In Honour of Phillip V. Tobias. New York: Wiley-Liss. p 249-260.

Kieser JA, van der Merwe CA. 1984. Classificatory reliability of the Carabelli trait in man. Arch Oral Biol 29:795-801.

Korenhof CAW. 1960. Morphogenetical aspects of the human upper molar: a comparative study of its enamel and dentine surfaces and their relationship to the crown pattern of fossil and recent primates. Utrecht: Uitgeversmaatschappij Neerlandia.

Krogman WM, İşcan MY. 1986. The Human Skeleton in Forensic Medicine. Springfield, minois: Charles C. Thomas. Lavelle CLB. 1970. Comparison of the deciduous teeth between Caucasoid, Negroid and Mongoloid population samples.

Dent Pract Dent Rec 21:121-124.

Lavelle CLB. 1973. Odontometric comparisons between maxillary premolars and molars of different ethnic groups. Hum Biol 45:123-135.

Lavelle CLB. 1978. An odontometric comparison of premolar morphology in man. Bull Group Int Rec Sci Stomatol Odontol $21: 209-222$.

Lavelle CLB. 1984. A metrical comparison of maxillary first premolar form. Am J Phys Anthropol 63:397403.

Lucas PW, Corlett RT, Luke DA. 1986. Postcanine tooth size and diet in anthropoid primates. Z Morphol Anthropol 76:253-276. 
Lysell L, Myrberg N. 1982. Mesiodistal tooth size in the deciduous and permanent dentitions. Eur J Orthodont 4:11-122.

Maier W. 1984. Tooth morphology and dietary specialisation. In: Chivers DJ, Wood BA, Bilsborough A, editors. Food

Acquisition and Processing in Primates. New York: Plenum. p 303-330.

Manly BFJ. 1991. Randomization and Monte Carlo Methods in Biology. London: Chapman and Hall.

Manly RS. 1951. Factors affecting masticatory performance and efficiency among young adults. J Dent Res 30:874-882.

Mayhall JT. 1992. Techniques for the study of dental morphology. In: Saunders SR, Katzenberg MA, editors. Skeletal

Biology of Past Peoples: Research Methods. New York: Wiley-Liss. p 59-78.

Mizoguchi Y. 1981. Variation units in the human permanent dentition. Bull Natl Sci Mus, Tokyo. Ser D 7:29-46.

Moorrees CFA. 1957. The Aleut Dentition: A Correlative Study of Dental Characteristics in an Eskimoid People.

Massachusetts: Harvard University Press, Cambridge.

Moorrees CFA, Reed RB. 1964. Correlations among crown diameters of human teeth. Arch Oral Biol 9:685-697.

Morris DH. 1981. Maxillary first premolar angular differences between North American Indians and non-North American Indians. Am J Phys Anthropol 54:431433.

Moss ML, Chase PS. 1966. Morphology of Liberian Negro deciduous teeth. Am J Phys Anthropol 24:215-229.

Moss ML, Chase PS, Howes Jr RI. 1967. Comparative odontometry of the permanent post-canine dentition of American whites and Negroes. Am J Phys Anthropol 27: 125-142.

O'Higgins P, Johnson DR, Flinn RM. 1990. The variability of patterns of sexual dimorphism in the hominoid skull. Experientia 46:670-672.

Oxnard CE. 1968. Primate evolution - a method of investigation. Am J Phys Anthropol 28:289-302.

Potter RHY, 1972. Univariate versus multivariate analysis in tooth size according to sex. J Dent Res $51: 716-722$.

Robinson JT. 1956. The dentition of the Australopithicinae. Transvaal Museum Memoirs No. 9.

Rosenzweig KA. 1970. Tooth form as a distinguishing trait between sexes and human populations. J Dent Res 49:1423-1426.

Smith RJ. 1999. Statistics of sexual size dimorphism. J Hum Evol 36:423-459.

Sofaer JA. 1970. Dental morphologic variation and the Hardy-Weinberg Law. J Dent Res 49:1505-1508.

Stern D, Skobe Z. 1985. Individual variation in enamel structure of human mandibular first premolars. Am J Phys Anthropol 68:201-213.

Swindler DR. 1976. Dentition of Living Primates. London: Academic Press.

Tabachnick BG, Fidell LS. 1996. Using Multivariate Statistics. New York: Harper and Row.

Townsend GC. 1976. Tooth size variability in Australian Aborigines. A descriptive and genetic study. PhD Thesis, University of Adelaide.

Townsend GC, Brown T. 1978. Heritability of permanent tooth size. Am J Phys Anthropol 49:497-504.

Turner II CG. 1985. Recent Hong Kong dentition: a probable southern affinity. J Hong Kong Archaeol Soc 11:142-146.

Turner II CG. 1989. Teeth and prehistory in Asia. Sci Am 260:88-96.

Turner II CG. 1990a. Major features of Sundadonty and Sinodonty, including suggestions about East Asian microevolution, population history, and late Pleistocene relationships with Australian aboriginals. Am J Phys Anthropol 82:295-317.

Turner II CG. 1990b. Microevolution of east Asian and European populations: a dental perspective. University of Tokyo Symposium: The Evolution and Dispersal of Modern Humans in Asia.

Turner II CG, Nichol C, Scott G. 1991. Scoring procedures for key morphological traits of the permanent dentition: The Arizona State University Dental Anthropology System. In: Kelley MA, Larsen CS, editors. Advances in Dental Anthropology. New York: Wiley-Liss. p 13-31.

Utermohle CJ, Zegura SL, Heathcote GM. 1983. Multiple observers, humidity, and choice of precision statistics: Factors influencing craniometric data quality. Am J Phys Anthropol 61:85-95.

Wood BA, Abbott SA. 1983. Analysis of the dental morphology of Plio-Pleistocene hominids. I. Mandibular molars: crown area measurements and morphological traits. J Anat 136:197-219.

Wood BA, Engelman CA. 1988. Analysis of the dental morphology of Plio-Pleistocene hominids. V. Maxillary postcanine tooth morphology. J Anat 161:1-35.

Wright RVS. 1994. The MV-NUTSHELL Brochure: a concise introduction to multivariate archaeology. Sydney: Author.

Yates F, Healey MJR. 1951. Statistical methods in anthropology. Nature 168:1116-1117. 